\title{
PREFACE: THE PRECARIOUS POLITICS OF GOING THERE
}

"How Ecuadorean journalists are teaching the Indians to read and write and like it." So begins "Alphabet in the Andes," a brief, English-language article written by an Ecuadorian author and published in the United States in 1945 and in Ecuador in 1949. ${ }^{1}$ The article-about Indians, literacy, and national life-not only gives a glimpse of ethnopolitics in its own moment but also offers an instructive opening anecdote for this early twenty-first-century book about rhetoric, visual culture, and indigeneity.

"Alphabet" tells the story of a literacy project run in the Quito area by the Ecuadorian Unión Nacional de Periodistas (UNP, National Journalists' Union). The first page of the article introduces us to its main characters: pitiable, malleable Indians and initially skeptical but quickly trained teachers. It gives as well a brief profile of one indigenous student, Rafael Llumiquinga, whom the strength of literacy moved from "unwashed" and unpleasantly aromatic into cleanliness and confidence. Utterly changed, the article notes, Llumiquinga "wrote to the local paper, saying that at last he felt like a man" (27).

After praising the work done by the UNP, "Alphabet" next describes a visit by literacy researchers from the United States sent to the project by the U.S. Office of the Coordinator of Inter-American Affairs (CIAA) and the Walt Disney Company. According to "Alphabet," the motion pictures those visitors brought to encourage literacy and improve hygiene "were almost too successful." They drew new students to the project in droves, overflowing rooms and lending a powerful new efficiency to the labor of teaching and learning (28).

As much as it celebrates the outcomes of the literacy projects discussedboth the pen-and-paper strategies of the UNP and the motion-picture efforts of the CIAA-Walt Disney expedition- "Alphabet" is also a celebration of influential visuality. The author, Miguel Albornoz, both praises the visual learning techniques employed in the program and emphasizes visual elements in his effort to draw in readers. He shows, in both areas, a significant faith in the power of seeing, and seeing anew. For Albornoz, the quality of 
literacy acquisition in the program is visible and tightly linked to an imagebased taxonomy. In his descriptions, indigeneity and modernity are visually marked poles existing in generative tension, both diametrically opposed and inextricably connected. He pictures illiterate Indians as dirty and ponchoclad, clumsily premodern in the shape of their hands and the set of their bodies. Yet they are eager for access to development and its bright lights, colors, and straight lines. In response, literate (nonindigenous) teachers provide printed flashcards and cartoon filmstrips that teach hygiene and modern skills. Accessing text and image transforms those miserable, mudcaked Indians into clean, bright-eyed, and trembling protocitizens. From ponchos, dirty fingernails, and crowded rooms to filmstrips, electric lights, and shining faces, acquiring literacy (and modernity) proves a thoroughly visual affair in Albornoz's hands.

Published first in the U.S. government periodical the Inter-American and then four years later in an Ecuadorian travel magazine, Ecuador, "Alphabet" had two different audiences. The Inter-American, the official organ of the CIAA, was distributed to U.S. State Department affiliates throughout the Americas. In Ecuador it would have been read by U.S. expatriates, members of the U.S. diplomatic corps, and Ecuadorians affiliated with those groups. The short-lived tourism magazine Ecuador, for its part, carried an appealing image of Ecuador to potential tourists both within the country and throughout the Americas. Its articles in Spanish and English situated Ecuador as a picturesque, culture-rich, and accessible nation. Both versions of the article, then, reached outward. They offered their story of literacy learning and national progress to an audience indirectly involved in the UNP's project yet, in many cases, intimately connected to it by their shared goals of modern development.

That sharp anxiety over modernity (and its lack) consumed both Ecuadorian political elites and the larger inter-American politics of development in the mid-twentieth century. In response, they launched a full-spectrum assault on the secondary signs of lingering rusticity, a status embodied particularly by indigenous peoples. "Alphabet," in other words, resonates topically with other Ecuadorian documents of its era. It resonates as well in its form: oriented primarily in textual terms-literacy rates and economic statistics, political projects and historical analyses-it relies heavily on the shaping force of seeing to spark identification and generate movement. The visual link that Albornoz makes between indigeneity and national development in his article was not, in other words, unusual. Yet his article's faith in the power of vision-to change Indians and inspire readers-offers a concise 
representative anecdote for the ways that seeing indigeneity and seeing national identity have long run parallel in Ecuadorian civic life.

Using artifacts such as "Alphabet in the Andes," this book traces textual and visual arguments about the nation threaded through more than a hundred years of Ecuadorian history. It takes up the specific example of Ecuador because that country has a long, rich, and well-documented history of explicit nation making and has consistently relied on the force of vision to carry that nation making forward. Like "Alphabet," in other words, Ecuador offers an evocative representative anecdote for the rhetorical intersections of visuality and nationalism. Giving close attention to the constitutive force of vision as demonstrated so powerfully by the Ecuadorian example, this study unravels the multivalent nature of nationalism and the ways its shaping, matter-making influence extends across representative forms.

These opening pages preface that analysis by calling attention to a set of parallel concerns visible in the image-saturated matrix of "Alphabet in the Andes." They suggest that the article's troubling confidence in the benefits of literacy, the reliability of interpretation, and the ability of U.S. American experts to "go there" - in this case, to Highland Ecuador-ought to unsettle and oblige scholars today. Though it might be easy to dismiss "Alphabet" as a historical example of misguided developmentalist propaganda, we would do better to engage "Alphabet" and artifacts like it as barometers for the power relations that infuse every interpretive project and haunt every effort to present a history.

$$
* * *
$$

"Alphabet" narrates literacy acquisition as provided through increasing levels of outside intervention. The nonindigenous Ecuadorian professionals of the UNP provide literacy training to indigenous communities pictured as uncivilized, unhygienic, and uncertain of their own potential. As Albornoz puts it, the members of the UNP began their project knowing "they had taken over a big job when they set out to teach the illiterates of the region to read and write." They discovered, however, "that the hardest part was to convince the misery-ridden highland Indians that it was possible for them to learn at all" (27). Indigenous Ecuadorians, according to Albornoz, desperately need outsiders to transform them into lettered people. They are passive, neglected subjects awaiting the benevolent intervention of others.

But indigenous communities are not the only ones in need of outside enhancement. U.S.-based literacy experts, funded by government agencies 
and corporate investment, further propel literacy learning forward through the latest in pedagogical technology, teaching Indians to "like it" at an ever more efficient pace. Albornoz describes their arrival using language that blends the CIAA's origins in the Second World War with its commitment to social hygiene, describing the arrival of "five new allies" in the "anti-illiteracy campaign": "Mickey Mouse, Donald Duck, . . . Jose Carioca, and two new cartoon characters called José and Ramón" (28). These Disney "reinforcements" make possible new progress in the battle against a social disease-illiteracythat "afflicts" nearly two-thirds of Ecuador's population. The full and modern might of United States arrives, once again, to carry the day.

The article's tale of intervention contains a sort of twentieth-century paternalism easily read, today, as problematic: imperialist, developmentalist, and neocolonial. It ought also, however, serve as a cautionary tale of the dangers of intervention and analysis. As U.S.-based rhetoric and visual-culture scholars increasingly imagine a wider and more complex field of inquiry for our work, we would do well to look closely at our uncomfortable kinship with predecessors such as "Alphabet" and the CIAA-Disney expedition.

In light of the tradition so baldly represented in "Alphabet," I am not confident that it is ever possible for U.S.-based or U.S.-trained scholars to completely transcend the history and perspectives of Euro-U.S. hegemony. Whether we restrict our inquiries to U.S. and European contexts or travel beyond them, we are inevitably informed by assumptions born of those contexts. ${ }^{2}$ The historical invasions and interventions of the Euro-U.S. worldpolitical colonialism, economic globalization, cultural imperialism-now touch most points of the globe. They color not only our analyses but also the scenes we encounter. We would be as foolish to deny how thoroughly they infuse our analytical means as we would be irresponsible to simply accept them as given. Whatever our subjects and their relative proximity to ourselves, scholarship is a messy, partial pursuit. Power relationships always infuse our historiography; our analytical lenses always skew as much as they reveal. Any rhetorical history, then, must incorporate tactics that trouble the scope and certainty of its own claims. We must, as the rhetorical historian LuMing Mao urges, produce scholarship that examines "the power dynamics within representation" across cultural and political borders. We must also call attention to how those power dynamics inevitably work within our own representations of rhetorical practice. ${ }^{3}$

Rhetorical historians moving beyond their field's long-standing focus on the United States and Europe have some good resources for considering the ethical quandaries of analysis. ${ }^{4}$ Yet the specific challenges of taking rhetorical 
historiography beyond its familiar Euro-U.S. sphere have only recently been the subject of direct discussion. ${ }^{5}$ Much remains to be considered. The existing scholarship generally encourages what Mao calls a "dialogic process": "troubling our own modes of thinking and being ... deftly moving between self and other, the local and the global, and the contingencies of the present and the historical imperatives of the past." ${ }^{6}$ Mao suggests that for both ethical and intellectual reasons, traveling rhetoricians need to critique, expand, or even set aside our learned habits of analysis-including our basic definitions of rhetoric's key concepts (e.g., persuasion, argument). Such analytical flexibility will allow more robust accounts of the diverse ways in which humans influence one another.

Yet even in the case of such careful research and writing, the "power dynamics within representation" remain active in our scholarship. For scholars researching and writing about Latin America, that means that we work constantly in light of the history encapsulated in "Alphabet." That history of influence and intrusion demands explicit strategies of recognition that-without descending into ethical paralysis-acknowledge how U.S. hegemony infuses scholarship. The next several pages offer my version of that strategy: a guide for reading Constitutive Visions as itself implicated in power dynamics and shaped by the limits of its analytical means and methods. Inspired by the troubling images at work in "Alphabet," it outlines three critical recognitions that ought to condition the reader's encounter with the text ahead. Those recognitions-invitations to rethink-map out the ways this text negotiates the precarious politics of traveling scholarship.

Recognition \#1: Dominant rhetorics are always haunted by practices that call the dispersion and coherence of that dominance into question.

The first lesson worth taking from "Alphabet" is a lesson of absence, of the part of the story that wasn't told but could have been. "Alphabet" narrates literacy acquisition as brought into indigenous communities from outside: concerned, well-meaning Ecuadorian journalists and foreign visitors provide programs backed by the full support of national governments and familiar corporations. That hopeful narrative, however, hides a more complicated story of literacy training denied and interrupted.

In "Alphabet," indigenous people are imagined as naturally and passively illiterate. Descriptions of rough hands, accustomed to wielding pick axes, not pencils, make clear just how foreign the delicate work of writing is to the beginning indigenous student. Yet the article also imagines indigenous 
people as protoliberal subjects, as hungry for a modern, Western life as soon as it is made available to them. When indigenous students realize that they can read and write, those awkward hands tremble with excitement; they write letters to the editor and appear in class the next day cleaned and manicured, where once they were dirty and unkempt. The article positions indigenous illiteracy as "the biggest enemy of Ecuadorean progress" and envisions the nonindigenous college students, journalists, and literacy experts who teach classes as saviors of both the individual Indians before them and the nation as a whole (28).

That tale-that literacy first became available to Ecuador's indigenous communities thanks to the good will of the nonindigenous state and private interest-covers over a longer and more complicated history. The truth is that at least a decade before the UNP, CIAA, and Walt Disney arrived, indigenous people-having been actively excluded from statefunded schooling-began building their own literacy programs and, for their trouble, faced violent retribution from landowners and bureaucratic repression from the government. ${ }^{7}$ Not telling (or not knowing) the history of that earlier struggle for literacy serves a specific purpose in "Alphabet," given the article's propagandist goals and elite, international audiences. It locates agency outside of indigenous communities to aggrandize and moralize the intervention of others. Taking at face value the story of literacy learning and national progress told in "Alphabet" and similar artifacts, then, would mean acquiescing to the same "power dynamics within representation" at work in the original piece. For a rhetorician today, the interaction and overlap of these conflicting projects-indigenous organizing, state-sponsored literacy projects, and U.S. foreign aid—ought themselves to provide the substance of analysis. Such an approach takes better account of the constitutive efforts of both hegemonic and subaltern groups; it tracks both dominant trends and counterforces, both successful and failed persuasion.

Giving attention to multiple levels of intervention is especially important in the Ecuadorian context, where so much of state formation occurred in the efforts of a light-skinned, European-identified, white-mestizo minority to solidify and maintain its political and social control. ${ }^{8}$ As the historical anthropologist A. Kim Clark argues, in the case of Ecuadorian nationstate formation, "neither dominant nor subordinate groups can be fully understood except in relation to each other." Indeed, Clark continues, even dividing Ecuadorian society into monolithic categories of "dominant" and "subordinate" risks erasing the internecine conflicts within and among subgroups that were also essential to evolving constitutions of 
Ecuadorian national identity. White-mestizo landowners in different regions sometimes saw their interests in conflict; urban elites viewed rural leaders as inferior rustics; indigenous caciques and "governors" used their privilege to participate in the networks of administration that exploited lower-class indigenous labor. Understanding the processes of Ecuadorian nation formation thus requires sorting through the messy accumulation of persuasive artifacts that negotiate, challenge, and attempt to secure often contradictory ideas of the national public. It also, as Clark implies, benefits from a rhetorical orientation. Those multiple relations among "dominant and subordinate groups should be thought of as characterized by contention, struggle and argument."9 Such focus on argument and dispute includes tracking persuasion in a number of registers and from across a variety of social positions, including those positions sometimes visible only between the lines of dominant discourse.

In what follows, then, analyses of elite efforts to imagine the nationstate are repeatedly interrupted by histories of resistance and discussions of rhetorical failure. Those turns toward the claims of subalterns and the infelicities of national narratives serve the scholarly interest of providing a robust history of a complex rhetorical ecology. They also, however, should remind readers that there are layers upon layers at work beneath the analyses offered here, that these tales are contested and contestable, and that they elide almost as much as they illuminate. Every switch of register or social position, in addition to signaling a shift in argument, should remind readers of interpretation's moral ambiguities and the stories yet to be explored.

Recognition \#2: U.S.-based interpretations of Ecuadorian contexts are in debt to Ecuadorian interpretations.

In "Alphabet" there is some sense of conversation between the Ecuador-based literacy projects run by the UNP and the U.S.-based expedition supported by Disney and the CIAA. Miguel Albornoz, the article's author, was an Ecuadorian - a liberal diplomat who later worked in the prodevelopment government of Galo Plaza Lasso (1948-52) and served as the Ecuadorian ambassador to the United Nations. The article, though written in English and published first in the United States, offers an Ecuadorian's perspective on literacy programs and spends its first half describing and praising the efforts of the UNP. At the same time, though Albornoz depicts the UNP's low-tech efforts as essential in a country with limited rural electrification, there is no question that such local projects pale in comparison to the motion 
picture-stoked modernity of the CIAA-Disney expedition. The UNP provides the quotidian labor; the CIAA and Disney push the cutting edge.

Certainly Albornoz had reason to present his article as a tale of glitzy U.S. intervention. His original audience (readers of the Inter-American) was primed for a pro-U.S. tone and a celebration of modernity in its most narrow definition. If Albornoz's article is a savvy response to a particular rhetorical situation, however, it also accedes to the expectations of its readers in ways that reinforce assumptions about unequal economies of knowledge. Albornoz writes as an insider-an Ecuadorian speaking of the Ecuadorian situation-yet he privileges an exterior method and the perspectives of outside intervention. He leaves out not only the history of indigenous-led organizing but also a rich Ecuadorian analytical milieu in which social scientists, labor organizers, local communities, and national politicians all actively debated the future implications of the so-called Indian problem. According to "Alphabet," the possibilities for progress in indigenous communities and in Ecuador as a whole are altered primarily by theories brought into the country from abroad (both the Laubach method used by the UNP and the films from the CIAA-Walt Disney); Ecuadorian theories and practices fade into the background. Choosing not to acknowledge the active debate within and emphasizing instead imported methods shapes the stories available about Ecuador and shifts the fulcrum of analysis outside the Ecuadorian context. Recognizing that shift and the reduced possibilities for productive synthesis that it entails ought, once again, to prompt recognition among present-day scholars from the United States: we will always carry the history of our analytical tools along with us but need not leave those tools unchanged.

Constitutive Visions emerges at the confluence of two powerful streams of scholarship. On the one hand, it draws deeply from a long history of rhetorical theorizing that includes consistent concern for the making and maintenance of the polis. On the other, it enters an Ecuadorian context flush with critical scholarship about the trials and mechanisms of national identity. Its challenge, then, is to allow the two to come together without letting one overwhelm the other. This is a slightly different challenge than the one posed by recent scholars who have questioned the applicability of the term "rhetoric" in non-Western contexts. Laying aside the rather thorny question of whether post-Columbian Latin America is or is not "Western," this dispute over the appropriate scope of rhetoric still risks leading rhetoricians' attentions astray because it assumes that rhetoric is a static concept-usually a somewhat thin version of the Greek Rhetorike. In that assessment, rhetoric 
is, indeed, incapable of approaching non-Western contexts. It would also, however, be unable to provide insight into the twenty-first-century United States or eighteenth-century Britain.

Thankfully, rhetoric need not be chained by its Greco-Roman roots. Instead, rhetoric can be approached as the English word applied to a large set of human practices: those forms of communication that have designs on the values, beliefs, and actions of others. ${ }^{10}$ The pages ahead regularly use rhetorical terms of art: topos, synecdoche, ethos. The meaning and purpose of those terms, however, is not primarily tethered to definitions articulated in the fourth century в.с.E. Instead, they are live analytical terms, charged with the energy of contemporary rhetorical theory and contemporary Ecuadorianist scholarship. At its best, the analysis here holds those two strands in close, generative proximity.

Taken in this sense, rhetoric is highly portable and its tools quite flexible. The important question is how sensitive the rhetorical method is-how well it captures fine-grained differences of context and moment. And the challenge for rhetorical analysis situated in long-ignored contexts is to calibrate its claims in relation to the existing body of scholarship, some of it quite rhetorical in nature, already in place.

Most anywhere rhetoricians might travel today, they will encounter prior and ongoing analytical work done by other scholars, local experts, and community members. Much of that work may pursue rhetorical questions or contain rhetorical implications. Mao's call for rhetoricians to find ways to "[trouble] our own modes of thinking and being" and "deftly [move] between self and other, the local and the global, and the contingencies of the present and the historical imperatives of the past" takes on new meaning in that context. ${ }^{11}$ While Mao may appear to emphasize an internal process of increased critical awareness on the part of the researcher, the fact of foregoing scholarship ought to remind us that such expansion does not occur in isolation. Interaction with others and others' analyses calls into question our existing ways of thinking and brings to light other understandings and methods. In the final product, those interlocutors appear not only in the form of citational support for the new argument but also as having profoundly influenced both the argument itself and the tools used to achieve it.

Ecuadorian and Ecuadorianist scholars have frequently treated the larger areas of concern addressed in this text. That long-term interest in the processes of nation making is, in fact, part of what makes Ecuador such a rich site for analyzing the rhetorical contours of national identity. Those scholars have also, often, asked and answered questions reasonably described 
as rhetorical in nature. ${ }^{12}$ Constitutive Visions, then, is far from the first study of rhetorical practice in Ecuador, and its understandings of what rhetoric is, how it circulates, and how it influences are shaped by those foregoing studies.

In the pages ahead, readers will encounter that potentially generative interaction in the frequent citation of both rhetorical theorists and Ecuadorianists and in the ways my analyses bring those two streams into conversation. Seeing those moments of confluence ought to remind readers that theories are live objects and that rhetorical theory needs to be alive to the influence of those histories and ideas already at work in new contexts. In this case, they draw attention to the ways that Ecuadorian scholars' assessments of national discourse drive and reshape the rhetorical terms and histories engaged here.

Recognition \#3: Processes of representation and identification take place over the long term; resistance and social change invisible at any given moment may become clear under a wider lens.

The hopeful assertions about the magic of literacy in "Alphabet" ring false today. Its depiction of drastic change occurring in a single day or through a single film focuses attention entirely on the moment of literacy acquisition and the programs that fostered that moment, eliding longer histories of oppression, intervention, and resistance. In the article, having learned to read and write, María Hermelinda Cuichán becomes a citizen, and an "old peon" announces that "his employers could not fool him on the payroll any more" $(27,28)$. "Alphabet" asks readers to accept a version of the "literacy myth" (the assumption that citizenship and economic opportunity flow naturally and inevitably from acquisition of literacy), reaching beyond the immediate gains made by individual students to imagine a nation transformed. ${ }^{13}$ The article gestures toward a larger history, one in which illiteracy disenfranchises and landowners exploit laborers. The racist strategies, colonial interventions, and structural inequalities that sustained that long history, however, are quickly (and implausibly) erased by the bright light of motion-picture literacy.

In "Pan-Historiography: The Challenges of Writing History Across Time and Space," Debra Hawhee and I argue for the value of pursuing histories that stretch across long periods. ${ }^{14}$ We suggest that, contrary to the common assumption that long-span histories must skim over details and textures, careful pan-historiography can in fact reveal textures and complexities that develop over time and might be hidden from a deep but narrowly focused analysis. Aware of the pitfalls illustrated by "Alphabet's" limited scope, 
Constitutive Visions attends to the long-term processes of national identity, tracing how changing tactics and shifting power relations both contest and serve an overall appearance of national coherence.

Bringing a long history into play sends rhetorical historians looking for other routes to literacy and obliges them to consider the processes that made illiteracy and indigeneity synonymous yet still tied indigeneity to national identity. It forces discussion of how Cuichán's claim that literacy makes her a citizen or the old peon's assertion that his employer will no longer be able to cheat him articulate with the long struggles over citizenship and conscripted labor surrounding those claims. Such pan-historiographic attention makes possible a more robust narrative. It positions Albornoz's empowered indigenous learners not only in light of the populist indigenous movements of the 1930 s and 1940 s but also in relation to the political shift in 1861 that made the franchise theoretically possible for literate Indians, in conversation with paintings of "miserable" Indians from the 188 os that helped establish the visual taxonomies in "Alphabet," and in tension with debates from the 1920 s over indigenous workers' capacity to make contracts.

This book, then, engages a pan-historiographic method to come as close as possible to the multivocality and rich texture of the history of nationalism it outlines. Each chapter draws together at least two periods of Ecuadorian history, usually a stretch in the mid-to-late nineteenth century and another in the mid-twentieth. The total span of the book runs from 1857 to 1947 , with the conclusion moving the analysis into the twenty-first century. Rather than offer a step-by-step history of those ninety-plus years, however, each chapter juxtaposes events and artifacts from different periods, using such oblique illumination to draw attention to both continuity and change. In addition to serving an analytical purpose, that pan-historiographic juxtaposition should remind readers of the far longer history into which the study intervenes. As Hawhee and I note, even the broadest pan-historiography represents a choice: "historiography always involves making selections." 15 In this study, the visibility of such selections should call the reader's attention to the lived complexities that exceed, sprawl beyond, and distend the circumferences drawn.

\section{Going There}

The narrative of literacy, modernity, and indigeneity in "Alphabet" is populated by Indians with red ponchos and shining black eyes, by upsetting aromas and 
rough hands, by cartoon characters, journalists, and the CIAA. The analyses presented in Constitutive Visions are not so different. Work-scarred hands and bright ponchos fill the canvases of artists and the speeches of political candidates and, in turn, the pages of this book. Neither is the text's origin in the U.S. academy so entirely different from that of the literacy experts described in "Alphabet." This study may not precisely carry the backing of the U.S. federal government or a major transnational corporation, as did the CIAAWalt Disney expedition, but it has, indirectly, received funding from the U.S. Department of Education and the Andrew W. Mellon Foundation. ${ }^{16}$ A blue U.S. passport grants visaless passage through the immigration checkpoint at Mariscal Sucre Airport in Quito, a privilege not reciprocated for Ecuadorianpassport holders standing in line on arrival in Miami or Houston. In both Quito and Madison, ATMs dispense crisp twenty-dollar bills on demand, but U.S. dollars buy much more in Ecuador than they do in the United States-a fact that might aid the Ecuadorian relatives of migrants living in the United States but not those who travel to the North. An academic title and affiliation with a U.S. university grant access to museums and archives in Ecuador, while many Ecuadorian scholars travel to the United States or Europe to earn degrees with sufficient caché to secure academic positions in their home country. Constitutive Visions is, in other words, not exactly unsponsored by the political and economic might of the United States.

The influence of the United States may not be what it once was, and Ecuadorians have long been roundly critical of their northern neighbors' assumptions of access (at least in private). Still, there is no question that travel from the United States to Ecuador, whether as a twentieth-century corporate-funded literacy expert or a twenty-first-century university-employed rhetorician, necessarily invokes troubling questions of power, access, and representation. If this study has absorbed some of the lessons made available through the jarring assumptions in "Alphabet" and sought to mitigate them by paying attention to resistance, by reading rhetorical theory in light of Ecuadorian scholarship, and by keeping in mind the long span of history, it certainly leaves other lessons as yet unlearned. Those missed lessons haunt these pages. Taken properly, however, that haunting can be productive. It pushes the reader to learn, again and again, the generative contradictions of rhetorical historiography. 